\title{
Gross visceral organs morphometry and carcass quality in broiler chicken fed Tannia (Xanthosoma sagittifolium) cocoyam
}

\author{
Mohammed Abdulrashid $^{1^{*}}$ and Leonard Nnabuenyi Agwunobi ${ }^{2}$ \\ 1Department of Animal Science, Ahmadu Bello University, Zaria, Nigeria. \\ ${ }^{2}$ Department of Animal Science, University of Calabar, Calabar, Nigeria. \\ *Corresponding author. Email: manarzh@gmail.com; Tel: +2347017955545.
}

\begin{abstract}
Copyright (@) 2019 Abdulrashid and Agwunobi. This article remains permanently open access under the terms of the Creative Commons Attribution License 4.0, which permits unrestricted use, distribution, and reproduction in any medium, provided the original work is properly cited.
\end{abstract}

Received 8th January, 2018; Accepted 4th February, 2018

\begin{abstract}
Tannia cocoyam meals (CCYM) as substitutes for maize were evaluated in a six week feeding trial, in order to determine and compare effects of dietary inclusion at $100 \%$ of tannia cocoyam and the levels of antinutritional factors present. Ninety-six broiler chickens at four weeks of age were randomly allotted in groups of 12 to one of the following diets. The dietary treatments contain 0, 25, 50 and 100\% CCYM of Tannia which comprised of raw sundried and boiled sundried forms. Proximate analyses of the test ingredient and that of maize was conducted. Antinutritional factor analyses of the test ingredients were also conducted. Carcass quality evaluation was also determined only on control groups and $100 \%$ (cocoyam inclusion). The results of proximate compositions indicated that tannia is higher in crude fibre, ash and nitrogen free extract. The weight of crop on raw tannia (31.70) was significantly lower $(p<0.05)$ than that of the control diet (32.45). The live weight, dressed weight and eviscerated weight and all other cut parts for both raw and boiled CCYM were similar $(p>0.05)$ to control. The weights of crop and intestine on $100 \%$ CCYM diets differed significantly $(p<0.05)$ with lower values on the control (32.45 and 112.08 respectively) and higher values on boiled sundried tannia (53.74 and 132.30 respectively). Significantly higher levels $(p<0.001)$ of anti-nutritional factors were observed on raw sundried tannia than the boiled sundried tannia. The carcass yield and organs weight were significantly higher $(p<0.05)$ on boiled sundried tannia as compared to that of raw sundried. Thus, better feed utilization on boiled tannia diets due to higher feeding value than raw sundried cocoyam. Therefore, boiled tannia could replace maize at $100 \%$ inclusion levels without any adverse effects on carcass characteristics, but lower levels of raw tannia is recommended due to higher content of antinutritional factors.
\end{abstract}

Keywords: Anti-nutritional factors, boiled tannia, broiler birds, carcass characteristics, organs weight, raw tannia.

\section{INTRODUCTION}

In most developing countries like Nigeria, there has always been short supply of grain for the populace. This problem is further compounded by the accelerated increase in human population which created pressure on every form of food supply. Maize and guinea corn are the major energy sources for poultry in Nigeria and they contribute about 60 to $80 \%$ of the total poultry diets (Apata and Babalola, 2012). It was also observed that acute shortage and high prices of feed ingredient is responsible for the present rise in prices of poultry and livestock feed in Nigeria (Ogbonna, 1997; Apata and Babalola, 2012), with the attendant rise in cost of meat and eggs. The increasing cost of conventional feedstuff coupled with high demand for grains for human consumption has stimulated interest in the use of nonconventional and readily available cheaper ingredients.

Cocoyam are perennial herbaceous plants which are known as edible aroids (Colocasia and Xanthosoma spp) 
belonging to the family of Araceae. Tannia (Xanthosoma sagittifolium) CCYM otherwise known as recent cocoyam consist of central corms from which cormels, fibrous roots and the shoots arise, and leaf consist of long erect petiole with a large lamina that appears sagittate with dark green colour. Cocoyam are cultivated mostly in various parts of the tropic as important food, especially in West Africa, the pacific, Asia and America (FAO, 1990). In African region, Nigeria, Egypt, Ghana and Ivory Coast, are among the important cultivators. In Nigeria, cocoyam is cultivated in Edo, Benue and Eastern states where they compete with yam. Although cocoyam is cultivated extensively in Nigeria, information is scarce on its uses as animals feed. It was shown that cocoyam is fairly good source of important nutrients, such as calcium and magnesium. Tannia has $39 \mathrm{mg}$ per $110 \mathrm{~g}$ of food (Ahaotu, 2018) and taro has $0.58 \mathrm{mg}$ per $100 \mathrm{~g}$ of food (Caicedo et al., 2018). Since taro was considered to have good nutrients with great productive potential in pig performance (Caicedo et al., 2018), as it was shown to completely replace maize effectively. However, it was suggested that tannia is referred to as new cocoyam (Ahaotu, 2018), and are now more important than taro cocoyam (Colocasia esculenta) being more popular (FAO,1990), due to superiority of their corms and cormels in terms of energy, proteins and mineral elements (Mwenye,2009). In addition, it was shown that tannia (Xanthosoma sagittifolium) is a high yielding and disease resistant variety (Apata and Babalola, 2012). Broiler starter performance and carcass characteristics fed sundried tannia at $10 \%$ inclusion levels were not affected (Ahaotu, 2018). Besides, it was postulated that substituting feed for broiler finisher with sundried tannia cocoyam at $15 \%$ did not affect the carcass quality (Cagas, 2017).

Cocoyam is an ancient crop grown throughout the humid area for its edible corms and leaves as well as for its traditional and ceremonial uses. Cocoyam is nutritionally richer than most of the tuber crops, and require little attention in terms of cultivation, yet it is not widely grown in the country owing to the low status and underutilization. It was shown that cocoyam has comparatively higher protein content than other tuber crops like cassava, yam and potato (Onwueme, 1982; Apata and Babalola, 2012; Okon et al., 2007). It was also observed that cocoyam has higher score for total essential amino acids comparable to cassava, yam and sweet potatoes (Standal, 1983, Caicedo et al., 2018; Apata and Babalola, 2012). The starch content of cocoyam is very readily digestible because of its small particle size (Onwueme, 1982; Cagas, 2017).

Cocoyam is recognized as cheap caloric sources on the basis of some agronomic and economic advantages which the crops enjoy over grain crops. The substitution of grains with roots and tubers is an economical question and roots have a great potential in many areas of the world as a major supplier of energy for animals (Abdulrashid and Agwunobi, 2009). Although the root and tuber meal is low in protein, its energy content is remarkably high and its price, relative to maize is low, hence the cost of production will be low. However, their effective and efficient exploitation is limited by presence of anti-nutritional factors that prevent digestion and absorption of nutrients. Hence these anti-nutrients must be eliminated before the use of cocoyam as feed ingredients in livestock diets. Thus, the study was conducted to determine and compare the effects of dietary inclusion at $100 \%$ of boiled and raw sundried tannia cocoyam meals on carcass and organs characteristics, as well as evaluating the levels of antinutritional factors present in both.

\section{MATERIALS AND METHODS}

The research was carried out at the Teaching and Research Farm of the University of Calabar, Calabar, Nigeria. The cocoyam corms (tannia) were obtained from local markets in Ikom and Odukpani both in Cross River State. The cocoyam (tannia) was washed separately to remove silts and other extraneous materials, then was separately utilized in either raw sundried or boiled sundried forms. The first part was processed as raw sliced into chips $(0.5$ to $1.0 \mathrm{~cm})$ and sundried for 2 to 3 days and milled. The other part was boiled whole for 30 minutes, sliced into chips $(0.5$ to $1 \mathrm{~cm})$ and sundried for 2 to 3 days and milled.

Ninety-six (96) Anak broiler chickens at 4 weeks old were individually weighed and randomly allotted into eight experimental diets with two replicates containing six (6) birds per replicate. The experimental diets were manufactured as isonitrogenous and isocaloric (Table 2) according to standard procedure. Tannia cocoyam was used separately in raw and boiled sundried forms to replace maize each at $0,25,50$ and $100 \%$ levels. The samples of the test materials, raw sundried tannia and boiled sundried tannia were analysed in the Biochemistry and Nutrition Laboratory, University of Calabar, Calabar, Nigeria for the determination of phytates, oxalate, tannin, saponin and HCN (AOAC, 1990). Proximate chemical analysis of fresh sundried tannia and that of maize were done according to AOAC (1990) procedure. Metabolizable energy was computed using standard formula by Pauzenga (1985). A conventional poultry house with deep litter floor pens was used. The treatments were arranged in a completely randomized design (CRD). Feed and water were provided ad libitum, and feeding trial lasted for six (6) weeks. Routine vaccination and necessary medications were administered on the birds as when necessary. At the end of the feeding trial by 10 weeks of age, 3 birds from the control, 3 from 100\% raw CCYM and another 3 from boiled CCYM were selected based on average weight in a group as a whole, starved for 24 hours, weighed and slaughtered by severing the jugular veins, birds were bled, dipped in hot water $\left(65\right.$ to $\left.90^{\circ} \mathrm{C}\right)$ for one minute and subsequently defeathered accordingly. The dressed 
Table 1. Proximate composition of Tanniacocoyam meal and maize.

\begin{tabular}{lcc}
\hline \multirow{2}{*}{ Parameters } & \multicolumn{2}{c}{$\%$ (DM Basis) } \\
\cline { 2 - 3 } & Tannia Meal & Maize \\
\hline Dry matter (DM) & 28.80 & 87.46 \\
Crude Protein (CP) & 5.68 & 9.80 \\
Crude Fiber (CF) & 4.50 & 2.04 \\
Ether extract (EE) & 1.50 & 4.80 \\
Ash & 5.50 & 1.39 \\
Nitrogen Free Extract (NFE) & 82.82 & 81.97 \\
${ }^{*}$ Energy ME (kcal/kg) & 3272.97 & 3665.18 \\
\hline
\end{tabular}

${ }^{\star}$ Calculated using Pauzenga method (1985).

Table 2. Ingredient composition of experimental diets (broiler finisher ration).

\begin{tabular}{lcccc}
\hline \multirow{2}{*}{ Ingredients } & \multicolumn{4}{c}{ Replacement levels } \\
\cline { 2 - 5 } & $\mathbf{0 \%}$ & $\mathbf{2 5 \%}$ & $\mathbf{5 0 \%}$ & $\mathbf{1 0 0 \%}$ \\
\hline Cocoyam Meal & 0 & 12 & 24 & 48 \\
Maize & 48 & 36 & 24 & 0 \\
Crayfish & 2.0 & 2.0 & 2.0 & 2.0 \\
Fish meal & 4.0 & 4.0 & 4.0 & 4.0 \\
Soya bean meal & 37 & 37 & 37 & 37 \\
Wheat offal & 5.0 & 5.0 & 5.0 & 5.0 \\
Bone meal & 2.0 & 2.0 & 2.0 & 2.0 \\
Salt & 0.5 & 0.5 & 0.5 & 0.5 \\
Vit. Min. Premix & 0.5 & 0.5 & 0.5 & 0.5 \\
Palm Oil & 1.0 & 1.0 & 1.0 & 1.0 \\
Total & 100 & 100 & 100 & 100 \\
& & & & \\
Calculated Analysis & & & & \\
Crude Protein (\%) & 22.63 & 22.03 & 21.43 & 20.83 \\
ME Kcal/kg & 3072.6 & 2977.8 & 2883 & 2793 \\
Calcium (\%) & 1.24 & 1.30 & 1.35 & 1.46 \\
Phosphorus (\%) & 0.79 & 0.82 & 0.82 & 0.82 \\
Lysine (\%) & 1.46 & 1.48 & 1.49 & 1.51 \\
Methionine (\%) & 0.46 & 0.45 & 0.44 & 0.42 \\
\hline
\end{tabular}

weight was then measured in kilogram using weighing scale, then carcass was sorted into parts and also internal organs were sorted separately, and subsequently weighed individually in grams.

\section{Data analyses}

The data obtained were subjected to analysis of variance (ANOVA) procedure in determining the significant difference. Duncan multiple range/post hoc test was used to separate treatment means found to be statistically significant. The difference between the effects of raw sundried and boiled sundried tannia was performed using student's T- test. A p-value of less than 0.05 was considered as significant, and the results obtained are expressed as mean \pm standard deviation. T- test was also used in comparing the raw sundried and boiled sundried tannia cocoyam.

\section{RESULTS}

The proximate chemical analysis of tannia cocoyam meal and that of maize are shown in Table 1. The diet containing maize was considered as control (Table 2). The results indicated that tannia cocoyam is higher in crude fibre, Ash and Nitrogen Free Extract as compared to maize. While 
Table 3. Carcass quality characteristics of broiler chickens fed raw tannia cocoyam meal.

\begin{tabular}{lcccc}
\hline Characteristics & Control & Raw tannia $(\mathbf{1 0 0} \%$ CCYM) & SEM & LOS \\
\hline Live weight $(\mathrm{kg})$ & $2.73 \pm 0.06$ & $1.78 \pm 0.24$ & 0.32 & NS \\
Dressed weight $(\mathrm{kg})$ & $1.90 \pm 0.29$ & $1.47 \pm 0.13$ & 0.38 & NS \\
Eviscerated weight $(\mathrm{kg})$ & $1.65 \pm 0.21$ & $1.20 \pm 0.15$ & 0.39 & NS \\
Head $(\mathrm{g})$ & $64.21 \pm 5.62$ & $47.49 \pm 2.25$ & 1.62 & $\mathrm{NS}$ \\
Neck $(\mathrm{g})$ & $79.92 \pm 7.79$ & $53.99_{ \pm} 1.63$ & 1.77 & $\mathrm{NS}$ \\
Back $(\mathrm{g})$ & $247.60 \pm 16.72$ & $166.33_{ \pm} 3.72$ & 2.61 & $\mathrm{NS}$ \\
Wing $(\mathrm{g})$ & $126.47 \pm 6.80$ & $72.04 \pm 2.71$ & 1.78 & NS \\
Thigh $(\mathrm{g})$ & $161.17 \pm 3.59$ & $117.64 \pm 8.26$ & 1.99 & NS \\
\hline
\end{tabular}

Values are means of three evaluation \pm SD. CCYM $=$ Cocoyam meal, SEM $=$ Standard error, LOS $=$ Level ofsignificance $(P<0.05)$, NS $=$ Not significant $(P>0.05)$.

Table 4. Organs weight of broiler chicken fed raw tannia cocoyam meal.

\begin{tabular}{lcccc}
\hline Parameters & Control & Raw tannia(100\% CCYM) & SEM & LOS \\
\hline Bile $(\mathrm{g})$ & $4.76 \pm 1.36$ & $3.86 \pm 0.69$ & 0.83 & NS \\
Proventriculus $(\mathrm{g})$ & $9.83 \pm 0.13$ & $7.28 \pm 0.65$ & 0.51 & $\mathrm{NS}$ \\
Heart $(\mathrm{g})$ & $8.00 \pm 1.57$ & $7.43 \pm 0.72$ & 0.87 & $\mathrm{NS}$ \\
Liver $(\mathrm{g})$ & $44.18 \pm 2.20$ & $43.23 \pm 3.59$ & 1.39 & $\mathrm{NS}$ \\
Kidney $(\mathrm{g})$ & $3.13 \pm 0.29$ & $2.65 \pm 0.51$ & 0.52 & $\mathrm{NS}$ \\
Lung $(\mathrm{g})$ & $11.17 \pm 2.40$ & $7.50 \pm 1.70$ & 1.17 & $\mathrm{NS}$ \\
Gizzard $(\mathrm{g})$ & $54.66 \pm 9.93$ & $47.88 \pm 3.01$ & 2.08 & $\mathrm{NS}$ \\
Crop $(\mathrm{g})$ & $32.45_{ \pm} 18.13$ & $31.70 \pm 15.36$ & 3.34 & $*$ \\
Intestine $(\mathrm{g})$ & $112.08 \pm 22.80$ & $125.68 \pm 3.09$ & 2.94 & $*$ \\
\hline
\end{tabular}

Values are means of three evaluation \pm SD. $C C Y M=$ Cocoyam meal, SEM $=$ Standard error, LOS $={ }^{*}$ Level ofSignificance $(P<0.05)$, NS $=$ Not significant $(P>0.05)$.

Table 5. Carcass quality characteristics of broiler chickens fed boiledtannia cocoyam meal (CCYM).

\begin{tabular}{lcccc}
\hline Characteristics & Control & Boiled tannia $(\mathbf{1 0 0} \%$ CCYM) & SEM & LOS \\
\hline Live weight $(\mathrm{kg})$ & $2.73 \pm 0.06$ & $2.00 \pm 0.17$ & 0.28 & NS \\
Dressed weight $(\mathrm{kg})$ & $1.90 \pm 0.29$ & $1.67 \pm 0.06$ & 0.30 & NS \\
Eviscerated weight $(\mathrm{kg})$ & $1.65 \pm 0.21$ & $1.40 \pm 0.04$ & 0.32 & $\mathrm{NS}$ \\
Head $(\mathrm{g})$ & $64.21 \pm 5.62$ & $50.07 \pm 0.93$ & 1.48 & $\mathrm{NS}$ \\
Neck $(\mathrm{g})$ & $79.92 \pm 7.79$ & $68.83 \pm 2.98$ & 1.90 & $\mathrm{NS}$ \\
Back $(\mathrm{g})$ & $247.60 \pm 16.72$ & $237 \pm 0.97$ & 2.43 & $\mathrm{NS}$ \\
Wing $(\mathrm{g})$ & $126.47 \pm 6.80$ & $111.07 \pm 0.87$ & 1.60 & $\mathrm{NS}$ \\
Thigh $(\mathrm{g})$ & $161.17 \pm 3.59$ & $146.85 \pm 4.60$ & 1.65 & $\mathrm{NS}$ \\
\hline
\end{tabular}

Values are means of three evaluation $\pm \mathrm{SD}$. CCYM = Cocoyam meal, SEM = Standard error, LOS =Level of significance $(P<0.05)$, NS $=$ Not significant $(P>0.05)$.

the carcass quality parameters and organs weight of broiler chicken on $100 \%$ sundried tannia cocoyam and the control diet are presented in Table 3 and 4 respectively. There were significant differences $(p<0.05)$ in organs weight on raw tannia with higher weight of crop and intestine on control and 100\% CCYM respectively. While the carcass quality parameters and organs weight in broiler chicken fed $100 \%$ boiled sundried tannia cocoyam and the control diet are presented in Table 5 and 6 respectively. There were significant increase in weight of crop and intestine on $100 \%$ boiled CCYM as compared to the control. The result on the levels of anti-nutritional factors in raw sundried and boiled tannia cocoyam are shown in Table 7, indicating significantly lower values of 
Table 6. Organs weight of broiler chickens fed boiled tannia cocoyam meal (CCYM).

\begin{tabular}{lcccc}
\hline Parameters & Control & Boiled tannia $(\mathbf{1 0 0} \%$ CCYM) & SEM & LOS \\
\hline Bile $(\mathrm{g})$ & $4.76 \pm 1.36$ & $3.96 \pm 0.43$ & 0.67 & $\mathrm{NS}$ \\
Proventriculus $(\mathrm{g})$ & $9.83 \pm 0.13$ & $10.44 \pm 0.40$ & 0.42 & $\mathrm{NS}$ \\
Heart $(\mathrm{g})$ & $8.00 \pm 1.57$ & $6.63 \pm 0.69$ & 0.87 & $\mathrm{NS}$ \\
Liver $(\mathrm{g})$ & $44.18 \pm 2.20$ & $45.49 \pm 0.89$ & 1.01 & $\mathrm{NS}$ \\
Kidney $(\mathrm{g})$ & $3.13 \pm 0.29$ & $2.81 \pm 0.81$ & 0.84 & $\mathrm{NS}$ \\
Lung $(\mathrm{g})$ & $11.17 \pm 2.40$ & $7.41 \pm 2.08$ & 1.22 & $\mathrm{NS}$ \\
Gizzard $(\mathrm{g})$ & $54.66 \pm 9.93$ & $53.86 \pm 4.13$ & 2.17 & $\mathrm{NS}$ \\
Crop $(\mathrm{g})$ & $32.45 \pm 18.13$ & $53.74 \pm 20.27$ & 3.58 & $*$ \\
Intestine $(\mathrm{g})$ & $112.08 \pm 22.80$ & $132.30 \pm 9.52$ & 3.28 & $*$ \\
\hline
\end{tabular}

Values are means of three evaluation $\pm S D$. CCYM $=$ Cocoyam Meal, SEM $=$ Standard error, LOS $={ }^{*}$ Level ofsignificance $(P<0.05)$, $\mathrm{NS}=$ Not significant $(\mathrm{P}>0.05)$.

Table 7. Levels of anti-nutritional factors in raw and boiled sundried tannia cocoyam meals.

\begin{tabular}{lcccc}
\hline Parameters & Raw tannia $(\mathbf{m g} / \mathbf{1 0 0 g})$ & Boiled tannia $(\mathbf{m g} / \mathbf{1 0 0 g})$ & SEM & LOS \\
\hline Phytate & $1.29 \pm 0.10$ & $0.15 \pm 0.01$ & 0.18 & $* *$ \\
Oxalate & $33.32 \pm 0.01$ & $21.70 \pm 0.02$ & 0.10 & $* *$ \\
Tannin & $1.52 \pm 0.02$ & $0.14 \pm 0.02$ & 0.12 & $* *$ \\
Saponin & $6.40 \pm 0.02$ & $4.30 \pm 0.10$ & 0.10 & $* *$ \\
Cyanide & $1.07 \pm 0.01$ & $1.01 \pm 0.20$ & 0.27 & $\mathrm{NS}$ \\
\hline
\end{tabular}

Values are means of three determinations $\pm S D$. ${ }^{*}$ Significantly Different $(P<0.01), S E M=$ Standard error of the mean, NS - Not significant.

Phytate, Oxalate, Tannin, Saponin in the boiled sundried tannia cocoyam as compared to raw sundried tannia cocoyam. However, there were no significant differences in the level of Cyanide in both raw and boiled sundried CCYM. There were significant differences with higher weight $(p<0.01)$ of neck, back, wing and thigh on those birds fed boiled sundried cocoyam as compared to those fed raw sundried tannia cocoyam diets (Table 8). Similarly, significantly higher weight $(p<0.05)$ of proventriculus, gizzard, crop and intestine was observed on group of birds fed boiled sundried tannia CCYM as compared to those on raw sundried tannia CCYM diets (Table 8).

\section{DISCUSSION}

The results obtained on the carcass quality parameters perhaps indicated that, birds apparently gained the highest weight in boiled tannia due to heat treatment through boiling. This could explain the reason for better performance on boiled tannia meals. Birds tends to have numerically lower carcass weight as shown in Table 3 , and significantly lower $(p<0.05)$ organs weight as indicated in Table 4 in raw tannia due to detrimental effect of raw cocoyam. This could be due to the fact that boiling was more effective than raw sun drying alone in reducing the level of anti-nutritional factors (Agwunobi et al, 2002). This may be due to inability of the birds to extract required nutrients from the feed because of the effects of antinutritional factors. However, this was an indication of poor process of digestion of food due to limiting factors. The best litter condition was observed in the pens housing the birds on the control diets, as a result of watery droppings observed on $100 \%$ raw CCYM diets. This was a consequence of good nutrient uptake/utilization.

The levels of the antinutritional factors analysed such as phytate, oxalate, tannin and saponin significantly differed $(p<0.01)$ with lower levels in boiled tannia. While the levels of Hydrogen cyanide ( $\mathrm{HCN}$ ) were not significantly different $(p>0.05)$ between the two cocoyam meals. This limiting factor leads to severe reduction in feed intake, nutrient utilization and weight gain (Apata and Babalola, 2012). Perhaps most of the anti-nutritional factors combines with food to form complexes and interfere with food and mineral absorption (Abdulrashid and Agwunobi.,2009). Phytates forms insoluble complexes as a consequence of the negatively charged phosphate in phtytic acid binds to metallic cations ( $\mathrm{Ca}, \mathrm{Fe}, \mathrm{K}, \mathrm{Mg}, \mathrm{Mn}$, and $\mathrm{Zn}$ ) with subsequent formation of mixed salt called phytin or phytate (Apata and Babalola, 2012). Thus, consequently render phosphorus and other important metallic minerals unavailable. Similarly, insoluble calcium oxalate are 
Table 8. Carcass yield of birds on boiled tannia compared to those on raw tannia cocoyam meal.

\begin{tabular}{lcccc}
\hline Parameters & Boiled tannia & Raw tannia $(\mathbf{1 0 0} \% \mathbf{C C Y M})$ & SEM & Level of significance \\
\hline Liveweight $(\mathrm{kg})$ & $2.00 \pm 0.24$ & $1.78 \pm 0.24$ & 1.71 & $\mathrm{NS}$ \\
Dressed weight $(\mathrm{kg})$ & $1.67 \pm 0.06$ & $1.47 \pm 0.13$ & 1.73 & $\mathrm{NS}$ \\
Eviscerated weight $(\mathrm{kg})$ & $1.40 \pm 0.04$ & $1.20 \pm 0.15$ & 1.74 & $\mathrm{NS}$ \\
Head $(\mathrm{g})$ & $50.07 \pm 0.93$ & $47.49 \pm 2.25$ & 1.03 & $\mathrm{NS}$ \\
Neck $(\mathrm{g})$ & $68.83 \pm 2.98$ & $53.99 \pm 1.63$ & 1.24 & $* *$ \\
Back $(\mathrm{g})$ & $237.00 \pm 0.97$ & $166.33 \pm 3.72$ & 1.25 & $* *$ \\
Wing(g) & $111.07 \pm 0.87$ & $72.04 \pm 2.71$ & 1.09 & $* *$ \\
Thigh $(\mathrm{g})$ & $146.85 \pm 4.60$ & $117.64 \pm 8.26$ & 2.07 & $* *$ \\
Organs weight $(\mathrm{g}):$ & & & & $\mathrm{NS}$ \\
Bile & $3.96 \pm 0.43$ & $3.86 \pm 0.69$ & 0.61 & $*$ \\
Proventriculus & $10.44 \pm 0.40$ & $7.28 \pm 0.65$ & 0.35 & $\mathrm{NS}$ \\
Heart & $6.63 \pm 0.69$ & $7.43 \pm 0.72$ & 0.69 & $\mathrm{NS}$ \\
Liver & $45.49 \pm 0.89$ & $43.23 \pm 3.59$ & 1.22 & $\mathrm{NS}$ \\
Kidney & $2.81 \pm 0.81$ & $2.65 \pm 0.51$ & 0.24 & $\mathrm{NS}$ \\
Lung & $7.41 \pm 2.08$ & $7.50 \pm 1.70$ & 1.12 & $*$ \\
Gizzard & $53.86 \pm 4.13$ & $47.88 \pm 3.01$ & 1.54 & $*$ \\
Crop & $53.74 \pm 20.27$ & $31.70 \pm 15.36$ & 3.45 & $*$ \\
Intestine & $132.30 \pm 9.52$ & $125.68 \pm 3.09$ & 2.05 & \\
\hline
\end{tabular}

Values are means of 3 determination $\pm S D$; Significantly Different $(P<0.01)$; Significantly Different $(P<0.05)$; SEM: Standard Error of the Mean; NS: Not Significantly Different.

formed when oxalic acid forms complexes known as oxalate salts which solidifies and irritates lining of the guts. The findings in this research study however established that cocoyam meal could therefore be acceptable and comparable to maize in feeding value. However, it was generally observed that birds on $100 \%$ raw sundried tannia passed more watery droppings than boiled due to poor utilization as a result of lower feeding value, hence significantly lower crop weight was observed. It is most likely that the heat treatment by boiling destroyed most of the anti-nutritional factors hence the better performance of birds on boiled than raw sundried cocoyam. The significant increase in weight of intestine on birds fed $100 \%$ boiled CCYM as compared to control could be attributed to better growth and development as a result of effective utilization. Similar finding was reported on rabbits by Agwunobi et al. (2000). The carcass yield and also weight of the proventriculus, gizzard, crop and intestine in boiled sundried tannia indicated better development than that of raw sundried this could be attributed to the lower effective control of temperature $\left(40^{\circ} \mathrm{C}\right)$ on sun drying than on heat from boiling water in reducing the level of antinutritional factors present (Agwunobi et al., 2002). This is an indication of better feed utilization on feeding boiled tannia cocoyam. Since boiling or heating could reduce the level of antinutritional factors present, thereby enhances the palatability, consumption and digestibility (Caicedo et al., 2018; Cagas, 2017). Thus, increases the bioavailability of the required nutrients and consequent positive development of carcass yield. Similar changes were reported on broiler starter birds by Ahaotu, (2018). In addition, better productivity of the boiled tannia cocoyam was apparently cost effective, as it was shown that the lowest cost of feed per $\mathrm{kg}$ was observed in 100\% CCYM inclusion level, as compared to that of maize (Abdulrashid and Agwunobi, 2012).

\section{Conclusion}

The crop and the intestine weight were lower in raw sundried tannia but higher in boiled sundried tannia, as compared to control. The carcass yield was not affected by the diets. The levels of all the antinutritional factors were found to be higher in raw sundried tannia with the exception of cyanide. The results obtained in this study revealed that boiled tannia cocoyam meal with proper processing will effectively replace maize at $100 \%$ level of inclusion as a major source of energy or crude fibre, calcium and other microminerals in finishing diets of broiler birds for maximum profit. While $100 \%$ raw sundried tannia is not recommended, since it seems to pose adverse effects on organs weight.

\section{CONFLICT OF INTEREST}

The authors declare that they have no conflict of interest. 


\section{REFERENCES}

Abdulrashid, M., \& Agwunobi, L. N. (2009). Taro cocoyam (Colocasia esculenta) meal as feed ingredient in poultry. Pakistan Journal of Nutrition, 8(5), 668-673.

Abdulrashid, M., \& Agwunobi, L. N. (2012). Tannia (Xanthosoma sagittifolium) cocoyam as dietary substitute for maize in broiler chicken. Greener Journal of Agricultural Sciences, 2(5),167171.

Agwunobi, L. N., Angwukam, P.O., Cora, O. O., \& Isika, M. A. (2002). Studies on the use of colocasia esculenta (taro cocoyam) in the Diets of weaned pigs. Tropical Animal Health and Production, 34(3), 241-247.

Agwunobi, L. N., Okafor, E. P., \& Ohazurike, N. (2000). Tannia cocoyam tuber meal (Xanthosoma sagittifolium) as a replacement for maize grain in the diets of rabbits. Global Journal of Pure and Applied Science, 6, 419-423.

Ahaotu, E. O. (2018). Performance and carcass characteristics of starter broiler birds fed processed cocoyam (Xanthosoma sagittifolium) corm Meal. Journal of Poultry Science and Technology, 06, (01), 05-09.

AOAC (1990). Association of Official Analytical Chemist. Official Methods of Analysis 15th Edn. AOAC. Inc. Arlington, Virginia 22201.

Apata, D. F., \& Babalola, T. O. (2012). The Use of Cassava, Sweet Potato and Cocoyam, and Their By- Products by NonRuminants. International Journal of Food Science and Nutrition Engineering, 2(4), 54-62.

Cagas, R. E. (2017). Meat Yield and Quality of Broiler Chickens Feed with Xanthosoma sagittifolium Corm Meal. American Scientific Research Journal for Engineering Technology and Science), 32(1), 181-191.

Caicedo, W., Vargas, J. C., Uvidia, H., Samaniego, E., Valle, S., \& Flores, L. (2018). Effect of taro (Colocasia esculenta (L.) Schott) silage on the productive performance of commercial pigs. Technical note. Cuban Journal of Agricultural Science, 52(2), 1-5.
FAO (1990). Food and Agriculture Organisation of the United Nations. Roots, tubers, plantain and bananas in human nutrition, Food and Nutrition series, 24, FAO code: 86, AGRIS: SO1 ISBN 92-5-102862-1. Rome.

Mwenye, O. J. (2009). Genetic diversity analysis and nutritional assessment of cocoyam genotypes in Malawi. M.Sc project, Department of Plant Science, University of the Free, Bloemfontein, South Africa.

Ogbonna, J. U. (1997). Nutritive Value of Cassava Peel Meal for Poultry. A Review. Proceedings of 2nd Annual Conference of Animal Science Association of Nigeria, Lagos, September, 1997.

Okon, B. I., Obi, M. B., \& Ayuk, A. A. (2007). Performance of quails (Cotunixcotunix japonica) fed graded levels of boiled sundried taro cocoyam Colocasia esculenta as a replacement to maize Medwell Outline Agric Journal, 2(6), 654-657.

Onwueme, I. C. (1982). The Tropical Tuber Crops. Utilization, Economics, and Future Prospects of Cocoyams. ELBSE dition. John Wiley \& Sons Ltd. p. 20.

Pauzenga, U. (1985). Chemistry and Nutrition. Journal. Zoo. Tech. International, 22-24.

Standal, B. R. (1983). Nutritive Value of Taro. In: T. T. Wang (ed.), A Review of Colocasia esculenta and its potential, (University of Hawaii press, Honolulu, Hawaii), Pp. 141-145. 